\title{
SINIR KIRINIM DALGASI TEORİSI İLE YARIM DÜZLEMDEN BESSEL IŞINLARININ KIRINIMI
}

Öz: Bu çalışmada, Sınır Kırınım Dalgası Teorisi (SKDT) yaklaşımı kullanılarak yutucu bir yarım düzlemin kenarından kırınan Bessel ışınlarının davranışı incelenmiştir. İlk olarak, vektör potansiyeli, Bessel ışınlarının yutucu yarım düzlemden kırınımı için, Helmholtz-Kirchoff integraliyle bağlantılı olarak yeniden düzenlenmiştir. Bu vektör potansiyelinden yola çıkılarak SKDT kırınım integrali elde edilmiş ve kırınan alanlar hesaplanmıştır. Daha sonra, ilgili koordinat dönüşümleri yapılarak kırınan alanlar küresel koordinatlarda elde edilmiştir. Ayrıca, Bessel ışınlarının ve hesaplanan kırınan alanların davranışı sayısal olarak elde edilen grafikler değerlendirilerek yorumlanmıştır.

Anahtar Kelimeler: Sınır Kırınım Dalgası Teorisi, Bessel 1şınları, Helmholtz-Kirchoff integrali, Kırınan alanlar.

\section{The Diffraction of the Bessel Beams from a Half Screen with Boundary Diffraction Wave Theory}

Abstract: In this study, the behavior of Bessel beams diffracted from the edge of a black half-plane was examined using the Boundary Diffraction Wave Theory (BDWT). Firstly, the vector potential was rearranged in relation to Helmholtz-Kirchoff integral for the diffraction of Bessel beams from the black half-plane. By using this vector potential, the BDWT diffraction integral was obtained and the diffracted fields were calculated. Then, the related coordinate transformations were made and the diffracted fields were obtained in spherical coordinates. Additionally, the behavior of the diffracted fields and Bessel beams was evaluated by interpreting the numerically derived graphs.

Keywords: Boundary Diffraction Wave Theory, Bessel beams, Helmholtz-Kirchoff integral, Diffracted fields.

\section{GIIRIŞ}

Bessel 1şınları, elektromanyetik, akustik veya yerçekimi 1şınımının genliği, birinci türden bir Bessel fonksiyonu ile tanımlanan bir alandır (McGloin ve Dholakia, 2005). Bessel 1şınları ilk olarak Durnin tarafından, Helmholtz denkleminin kesin çözümü olarak ortaya konulmuştur. Bessel 1şınları düzlemsel dalgalar gibi fiziksel olarak oluşturulamaz ve bir engele çarptıktan sonra kendini yeniden yapılandırma özelliğine sahiptir. Bir Bessel 1şınını tanımlayan matematiksel fonksiyon, silindirik koordinatlarda Helmholtz denkleminin değişkenlerine ayrıştırılabilen çözümünde karşımıza çıkan Bessel diferansiyel denkleminin bir çözümüdür. Lazerlerin sıra dışı bir çeşidi olan Bessel 1şınları, bir noktanın etrafını eş merkezli halkalarla çevirerek daire oluşturur (Yu ve Dou, 2008). Ancak bu 1şınların en önemli karakteristiği dağılmadan yayılmasıdır. X-1şınları, Bessel 1şınlarının süperpozisyonlarının sabit hızla

\footnotetext{
"Bursa Uludağ Üniversitesi, Mühendislik Fakültesi, Elektrik-Elektronik Mühendisliği Bölümü, 16059, Görükle, Nilüfer-BURSA İletişim Yazarı: Uğur Yalçın (uyalcin@uludag.edu.tr)
} 
ilerleyenidir. Gauss 1şınlarının tam aksine Bessel ışınlarının enerji yoğunluğu yayılma ekseni çevresinde sinırlıdır.

Young (1802)'a göre kırınımın oluşma sebebi, düzgün ilerleyen bir dalga ile açıklık yüzeyinden yansıyan bazı dalgaların süperpozisyonudur. Maggi-Rubinowicz birbirlerinden bağımsız olarak Young'ın teorisini matematiksel hale getirip, çizgisel bir integrale indirgeyerek sınır kırınım dalgası ve geometrik dalga olarak iki parçaya ayrıştırmışlardır (Marchand ve Wolf, 1962). Maggi-Rubinowicz tarafindan elde edilen potansiyel fonksiyonu, çeşitli tipteki gelen alanlar için Miyamoto ve Wolf tarafından genelleştirilmiştir (Miyamoto ve Wolf, 1962a), (Miyamoto ve Wolf, 1962b).

Elektromanyetik saçılma problemleri ile ilgili yapılan son çalışmalarda saçıcı yüzeylerin kenarından kırınan alanların hesabında SKDT yaklaşımı sıklıkla kullanılmaya başlanmıştır (Yalçın, 2009a), (Yalçın, 2009b), (Yalçın, 2011). SKDT yaklaşımının kısıtlamaları nedeniyle sadece yutucu yüzeylerden saçılan alanların hesabı yapılabilmektedir (Yalçın, 2009), (Altıngöz ve Yalçın, 2013). Bu yaklaşımı kullanarak yutucu bir yarım düzlemin kenarından kırınan Gauss ışın demeti alanların hesabını ilk olarak Otis ve Lit yapmıştır (Otis ve Lit, 1975).

$\mathrm{Bu}$ çalışmada, Bessel ışınlarının yutucu bir yarım düzlemin kenarından kırınımı SKDT yaklaşımıyla incelenmiştir. İlk olarak, gelen dalga Bessel ışını olacak şekilde SKDT nin vektör potansiyeli bu problemin çözümü için yeniden düzenlenmiştir. Daha sonra, elde edilen bu vektör potansiyeli kullanılarak yutucu yarım düzlemin kenarından kırınan alanlar hesaplanmıştır. Sayısal sonuçlar kısmında ise, hesaplanan kırınan alanlar ve Bessel ışınları grafiklerle karşılaştırılmış, sonuçlar yorumlanmıştır. Literatürde reel değerli ışınım demetlerinin bir engelden kırınımı ile ilgili çok çeşitli çalışmalar bulunmaktadır. Bununla birlikte, kompleks değerli ışınlardan sadece Gauss ışınlarının kırınımı ile ilgili çalışmalar mevcuttur. Bu çalışma ise kompleks değerli bir ışın demeti olan Bessel ışınlarının yarım düzlemden kırınımının incelendiği, bizim bildiğimiz kadarıyla yeni bir çalışma olacaktır.

Zaman faktörü bu çalışmada $e^{j \omega t}$ olarak alınacaktır.

\section{SINIR KIRINIM DALGASI TEORISİ}

$S$ kapalı yüzeyi ile sınırlandırılan bir hacim içerisindeki herhangi bir $P$ noktasındaki alan dağılımı

$$
U(P)=\iiint_{S} \vec{V}(Q, P) \cdot \vec{n} d S
$$

Helmholtz-Kirchhoff integrali ile verilebilir. Burada $\vec{n}$ kapalı yüzeyin normal birim vektördür. $\mathrm{Bu}$ integral denklem homojen Helmholtz denkleminin bir çözümüdür ve Stokes teoremi kullanılarak iki parçaya ayrılabilir.

$$
U(P)=U_{B}(P)+U_{G O}(P)
$$

Yukarıda verilen (2) eşitliği SKDT yaklaşımının temel eşitliğidir. Bu eşitlikte görülen ilk terim, $A$ açıklık yüzeyinin $\Gamma$ sınırından kırınan alanı temsil eder (Şekil 1) ve aşağıdaki integral eşitliği ile verilebilir. 


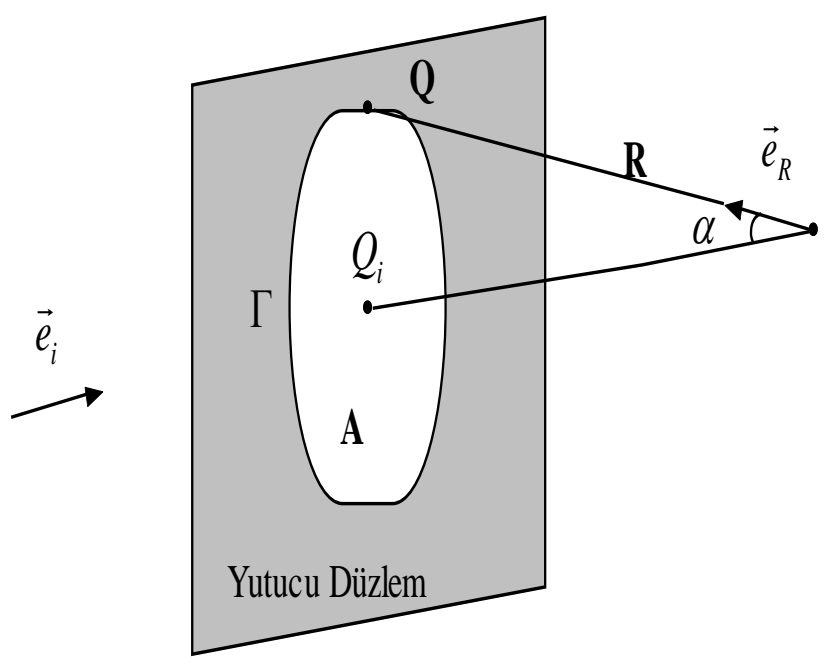

Şekil 1:

Sinır Kırınım Dalgası Teorisi'nin Geometrisi

$$
U_{B}(P)=\int_{\Gamma} \vec{W}(Q, P) \cdot \vec{l} d l
$$

Bu eşitlikte görülen $\vec{l}$ açıklık yüzeyinin $\Gamma$ sınırına ait uzunluk elemanının birim vektörü olmak üzere, aynı eşitlikteki vektör potansiyeli sembolik olarak,

$$
\vec{W}(Q, P)=\frac{1}{4 \pi} \frac{e^{-j k R}}{R}\left[\vec{e}_{R} \times \frac{\nabla_{Q}}{\left(-j k+\vec{e}_{R} \cdot \nabla_{Q}\right)} U(Q)\right]
$$

şeklinde verilebilir (Miyamoto ve Wolf, 1962a), (Miyamoto ve Wolf, 1962b). Burada $k$ boş uzayın dalga sayısıdır. (2) eşitliğinde görülen ikinci terim ise vektör potansiyelinin tekillikleri olup Geometrik Optik (GO) alanlarının katkısını temsil etmektedir.

\section{YARIM DÜZLEMIN KENARINDAN KIRINAN BESSEL ALANLARININ HESABI}

Boş uzay için skaler dalga denklemi

$$
\left(\nabla^{2}-\frac{1}{c^{2}} \frac{\partial^{2}}{\partial t^{2}}\right) U(\vec{r}, t)=0
$$

olarak verilebilir. Burada $c$ ışığın boş uzaydaki hızıdır. Bu denklemin bir çözümü kaynaklardan bağımsız olan $z \geq 0$ bölgesi için

$$
U(x, y, z \geq 0, t)=u_{i} e^{-j(\beta z-\omega t)} \int_{0}^{2 \pi} A(\phi) e^{-j \alpha(x \cos \phi+y \sin \phi)} d \phi
$$

şeklindedir (Durnin, 1987). Burada, $\alpha$ zayıflama sabiti $\beta$ ise faz sabitidir. $\beta^{2}+\alpha^{2}=(\omega / c)^{2}=k^{2}$ ve $A(\phi)$ ise $\phi$ nin keyfi kompleks bir fonksiyonudur. $\beta$ reel olduğunda (6) eşitliği kırınımsız alanları temsil eder. Sadece kırınımsız alanlar için bu eşitlik 
Yalçın U.: Sınır Kırı. Dalg. Teorisi ile Yarım Düz. Bess. Işınır. Kırın.

eksenel simetriye sahiptir ve $A(\phi), \phi$ den bağımsız olup orantısal olarak $1 / 2 \pi$ seçilebilir. Böylece,

$$
\begin{aligned}
U(x, y, z \geq 0, t) & =u_{i} e^{-j(\beta z-\omega t)} \frac{1}{2 \pi} \int_{0}^{2 \pi} e^{-j \alpha(x \cos \phi+y \sin \phi)} d \phi \\
& =u_{i} e^{-j(\beta z-\omega t)} J_{0}(\alpha \rho)
\end{aligned}
$$

şeklinde elde edilebilir. Burada $\rho^{2}=x^{2}+y^{2}$ ve $J_{0}(\alpha \rho)$ birinci tür sıfırıncı mertebeden Bessel fonksiyonudur.

Çözüm (7) eşitliğinde $\alpha=0$ için düzlemsel dalgaya indirgenir. Eğer $0<\alpha \leq \omega / c$ ise çözüm kırınımsız alanları temsil eder. Bessel ışınının efektif genişliği $\alpha$ ile belirlenir ve $\beta=0$ için $\alpha=\omega / c$ olur ki bu mümkün olan maksimum değeridir (Durnin, 1987). Şekil 2'de $J_{0}(\alpha \rho)$ için yoğunluk dağılımı grafiği verilmiştir.

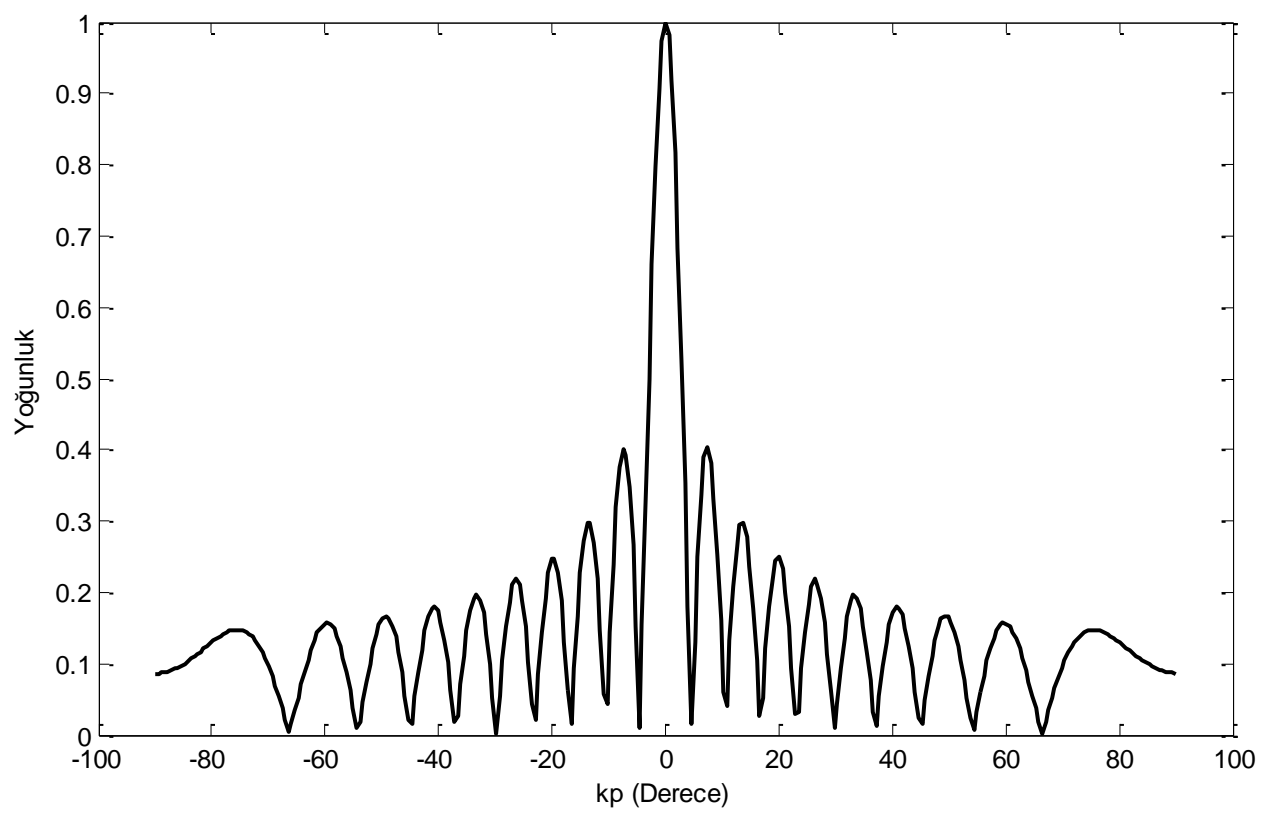

Şekil 2:

$J_{0}(\alpha \rho)$ için yoğunluk dă̆ılımı grafiğ $i$

Kırınım geometrisi Şekil 3'de verilmiştir. Burada $\vec{r}$ gözlem noktasının konum vektörüdür ve

$$
\vec{r}=x \vec{e}_{x}+y \vec{e}_{y}+z \vec{e}_{z}
$$

olarak yazılabilir. Gelen alana ait birim vektör ise 


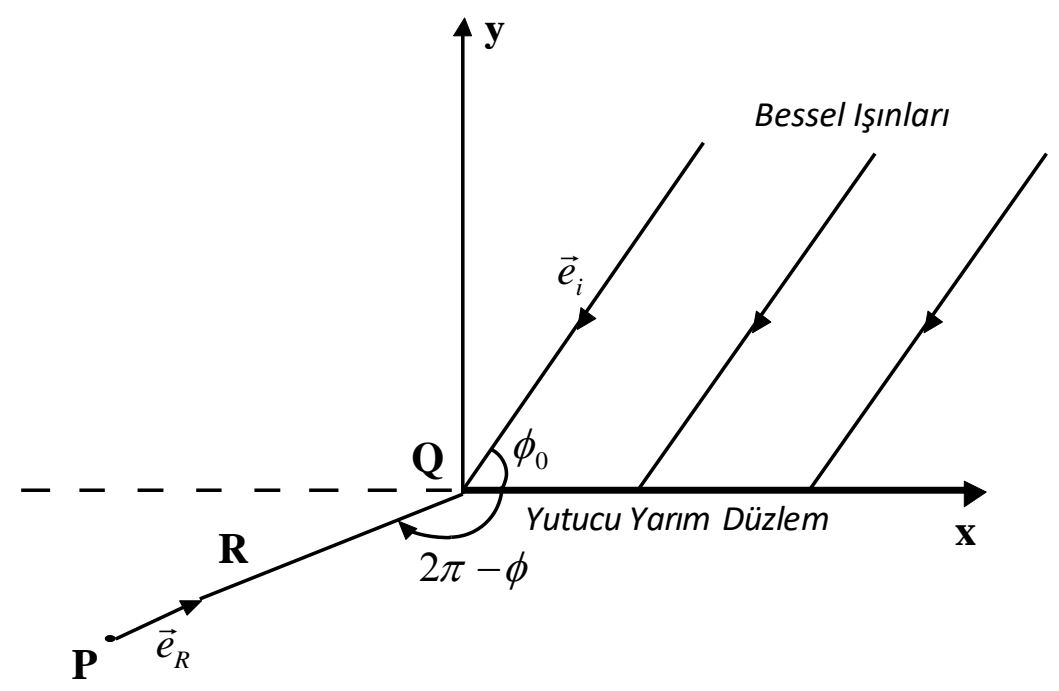

Şekil 3:

Yutucu Yarım Düzlem için Kırınım Geometrisi

$$
\vec{e}_{i}=-\cos \phi_{0} \vec{e}_{x}-\sin \phi_{0} \vec{e}_{y}
$$

şeklindedir. $k^{2}=\alpha^{2}+\beta^{2}$ denkleminde $\beta=0$ alınarak fiziksel probleme uygun olan $\alpha=k$ değeri elde edilebilir. Böylece yutucu yarım düzlem üzerine gelen fazör alan ifadesi,

$$
U_{i}(P)=u_{i} J_{0}(k \rho)
$$

olarak bulunabilir. Yutucu yarım düzlemden kırınan alan ifadesi (3) eşitliğinden bulunabilir. İlk olarak, yutucu yarım düzlem için ilgili vektör potansiyeli bulunacaktır.

İkincil kaynak noktası $Q$ orijinde olduğundan, $x^{\prime}=y^{\prime}=0$ dir. Böylece, $U_{i}(Q)$ 'nun gradyeni $Q$ noktasinda

$$
\nabla_{Q} U(Q)=-j k u_{i} J_{0}(k \rho) \vec{e}_{i}
$$

şeklinde bulunabilir. Neticede bu problem için vektör potansiyeli (4) eşitliğinden

$$
\vec{W}(Q, P)=u_{i} J_{0}(k \rho) \frac{1}{4 \pi} \frac{e^{-j k R}}{R}\left(\frac{\vec{e}_{R} \times \vec{e}_{i}}{1+\vec{e}_{R} \cdot \vec{e}_{i}}\right)
$$

olarak hesaplanabilir. Şekil 4' teki geometriden ilgili birim vektörler

$$
\begin{aligned}
& \vec{e}_{R}=-\cos \phi \vec{e}_{x}-\sin \phi \vec{e}_{y} \\
& \vec{l}=-\vec{e}_{z}
\end{aligned}
$$

şeklinde yazılabilir. Buradan, (9) ve (13) eşitlikleri göz önüne alınarak 
Yalçın U.: Sınır Kırı. Dalg. Teorisi ile Yarım Düz. Bess. Işınır. Kırın.

$$
\frac{\left(\vec{e}_{R} \times \vec{e}_{i}\right) \cdot \vec{l}}{1+\vec{e}_{R} \cdot \vec{e}_{i}}=\frac{-\sin \left(\phi-\phi_{0}\right)}{1+\cos \left(\phi-\phi_{0}\right)}=-\tan \left(\frac{\phi-\phi_{0}}{2}\right)
$$

hesaplanabilir. Böylece kırınım integrali, (3) eşitliğinde (12), (13) ve (14) kullanılarak

$$
U_{B}(P)=-u_{i} J_{0}(k \rho) \frac{1}{4 \pi} \tan \left(\frac{\phi-\phi_{0}}{2}\right) \int_{\Gamma} \frac{e^{-j k R}}{R} d l
$$

olarak bulunabilir. Bu problem için $R=\left[x^{2}+y^{2}+\left(z-z^{\prime}\right)^{2}\right]^{1 / 2}$ ve $d l=d z^{\prime}$ şeklindedir. Bu nedenle kırınım integrali yeniden yazılırsa,

$$
U_{B}(P)=-u_{i} J_{0}(k \rho) \frac{1}{4 \pi} \tan \left(\frac{\phi-\phi_{0}}{2}\right) \int_{z^{\prime}=-\infty}^{\infty} \frac{e^{-j k R}}{R} d z^{\prime}
$$

elde edilebilir. (16) eşitliği Hankel fonksiyonu cinsinden $\left(z-z^{\prime}\right)=\rho s h \gamma$ değişken dönüşümü kullanılarak,

$$
\int_{c} e^{-j k c h \gamma} d \gamma=\frac{\pi}{j} H_{0}^{(2)}(k \rho)
$$

eşitliği de göz önüne alınarak $\rho=\left[x^{2}+y^{2}\right]^{1 / 2}$ olmak üzere,

$$
U_{B}(P)=-u_{i} \frac{1}{4 j} \tan \left(\frac{\phi-\phi_{0}}{2}\right) H_{0}^{(2)}(k \rho) J_{0}(k \rho)
$$

şeklinde bulunabilir. $\rho=r \sin \theta$ dönüşümü yapılarak (18) ifadesi küresel koordinatlara dönüştürülebilir. Hankel fonksiyonunun Debye asimptotik açılımı $X \rightarrow \infty$ için

$$
H_{0}^{(2)}(X) \approx \sqrt{\frac{2}{\pi}} \frac{e^{-j X+j \pi / 4}}{\sqrt{X}}
$$

olmak üzere, yutucu yarım düzlemin kenarından kırınan alan $X=k r \sin \theta$ dönüşümü kullanilarak,

$$
U_{B}(P)=-u_{i} \frac{1}{2 \sqrt{2 \pi}} J_{0}(k r \sin \theta) \tan \left(\frac{\phi-\phi_{0}}{2}\right) \frac{e^{-j k r \sin \theta-j \pi / 4}}{\sqrt{k r \sin \theta}}
$$

olarak bulunabilir.

\section{SAYISAL SONUÇLAR}

$\mathrm{Bu}$ bölümde, Bessel ışınlarının yutucu yarım düzlemden kırınımı sayısal sonuçlarla tartış1lacaktır. Sayısal olarak çizdirilen grafiklerde $u_{i}$ birim genlik ve Bessel dalgaların yüzeye geliş açısı $\phi_{0}=\pi / 3$ seçilmiştir. Diğer ilgili parametreler ise fiziksel problemlere uygun olarak 
$k=20 \pi$ ve $r=\frac{30}{k}$ olarak alınmıştır. (Altıngöz ve Yalçın, 2013), (Yalçın ve Altıngöz 2017). Tüm grafikler $\phi=0$ düzleminde, $\theta \in\left(-\frac{\pi}{2}, \frac{\pi}{2}\right)$ aralığında çizdirilmiştir.

İlk olarak (10) eşitliğinde yukarıda verilen sayısal değerler kullanılarak gelen alanların grafiği Şekil 4'teki gibi elde edilmiştir.

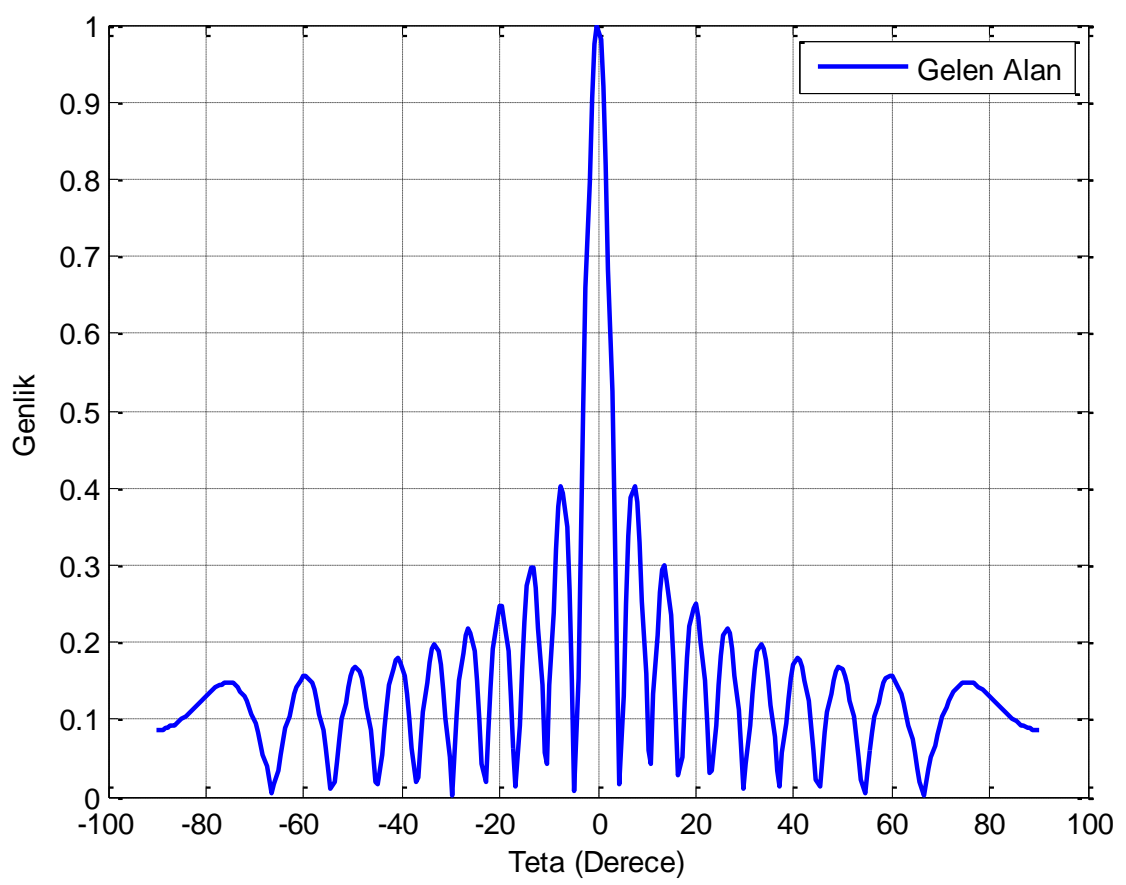

Şekil 4:

Gelen Alanlar

Şekil 5'te ise kırınan alanların $\theta^{\prime}$ ya bağlı değişimi verilmiştir. Bu grafikte (20) eşitliğinin mutlak değeri alınıp, yukarıda verilen sayısal değerler kullanılarak çizdirilmiştir.

Şekil 6'da $r=10 / k$ olarak değiştirilmiş ve yukarıda verilen sayısal değerler kullanılarak kırınan alanların grafiği yeniden çizdirilmiştir. Elde edilen şekilden salınımda genişlemeler olduğu görülmüş̧ür.

Şekil 7'de yukarıda verilen sayısal değerler kullanılarak gelen, kırınan ve toplam alanlarının $\theta$ ' ya göre değişen grafikleri karşılaştırmalı olarak verilmiştir. Şekilde kırınımsız alanlar olarak bilinen Bessel 1şınlarının yutucu yarım düzlemden kırındığı açık bir şekilde görülmektedir.

Son olarak, Şekil 8'de $r=10 / k$ ve $\phi_{0}=\pi / 6$ değerleri için gelen, kırınan ve toplam alanlarının $\theta$ ile değişimleri yeniden çizdirilmiştir. Şekil 8'den görüldüğü gibi salınımda beklendiği gibi genişlemeler olduğu tespit edilmiştir. 
Yalçın U.: Sınır Kırı. Dalg. Teorisi ile Yarım Düz. Bess. Işınır. Kırın.

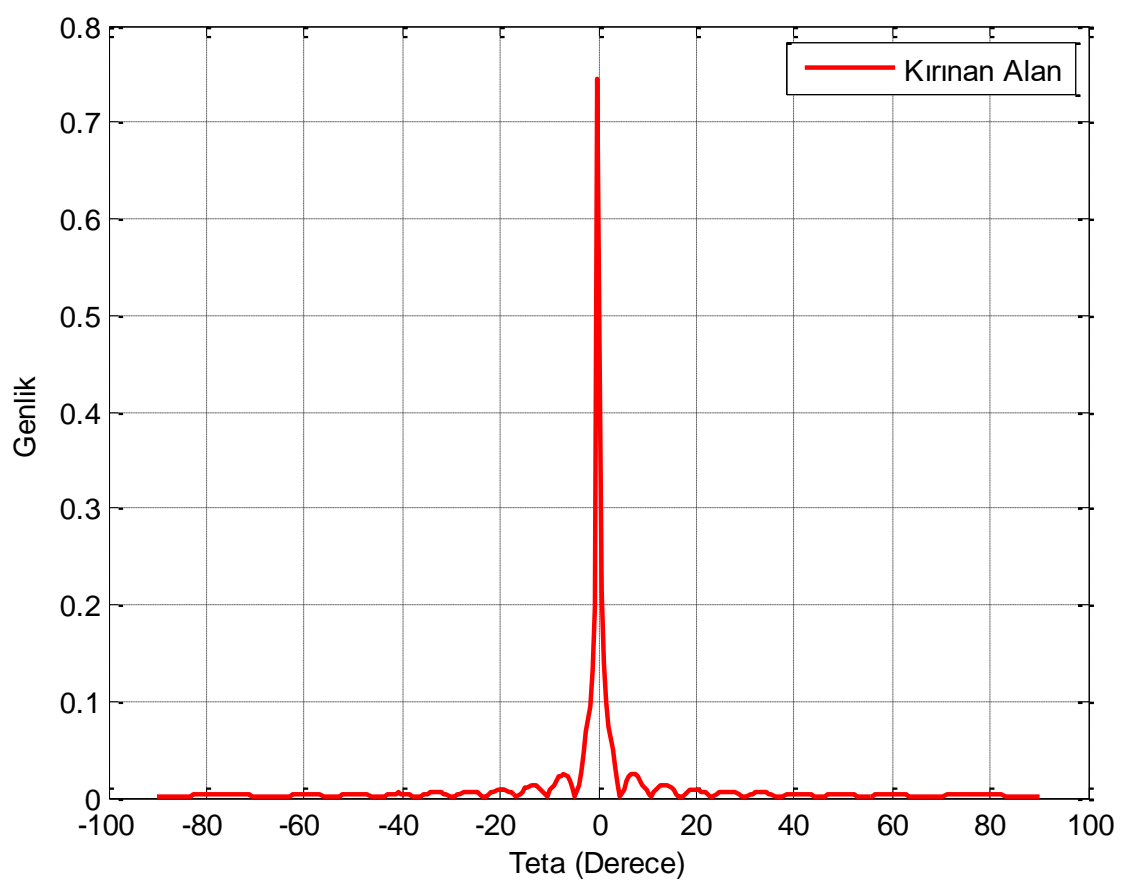

Şekil 5:

Kırınan Alanlar $(r=30 / k)$

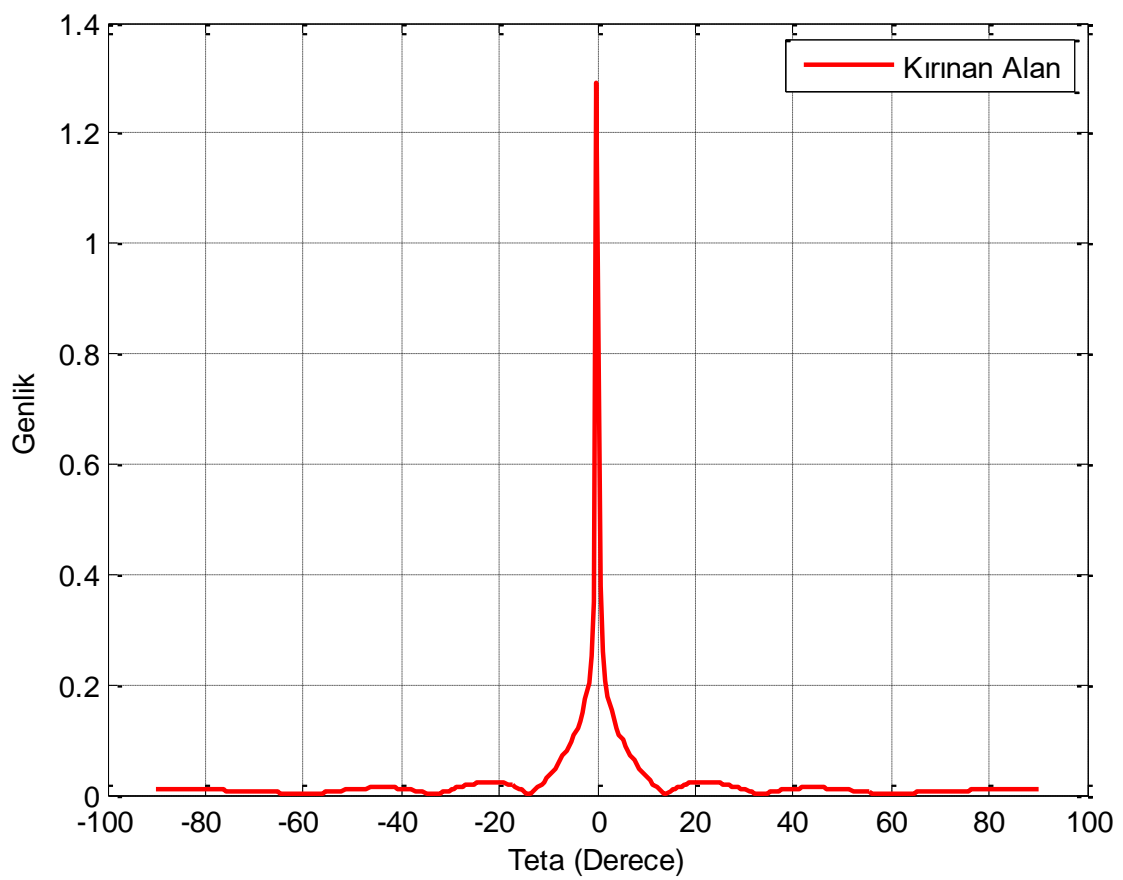

Şekil 6:

Kırınan Alanlar $(r=10 / k)$ 


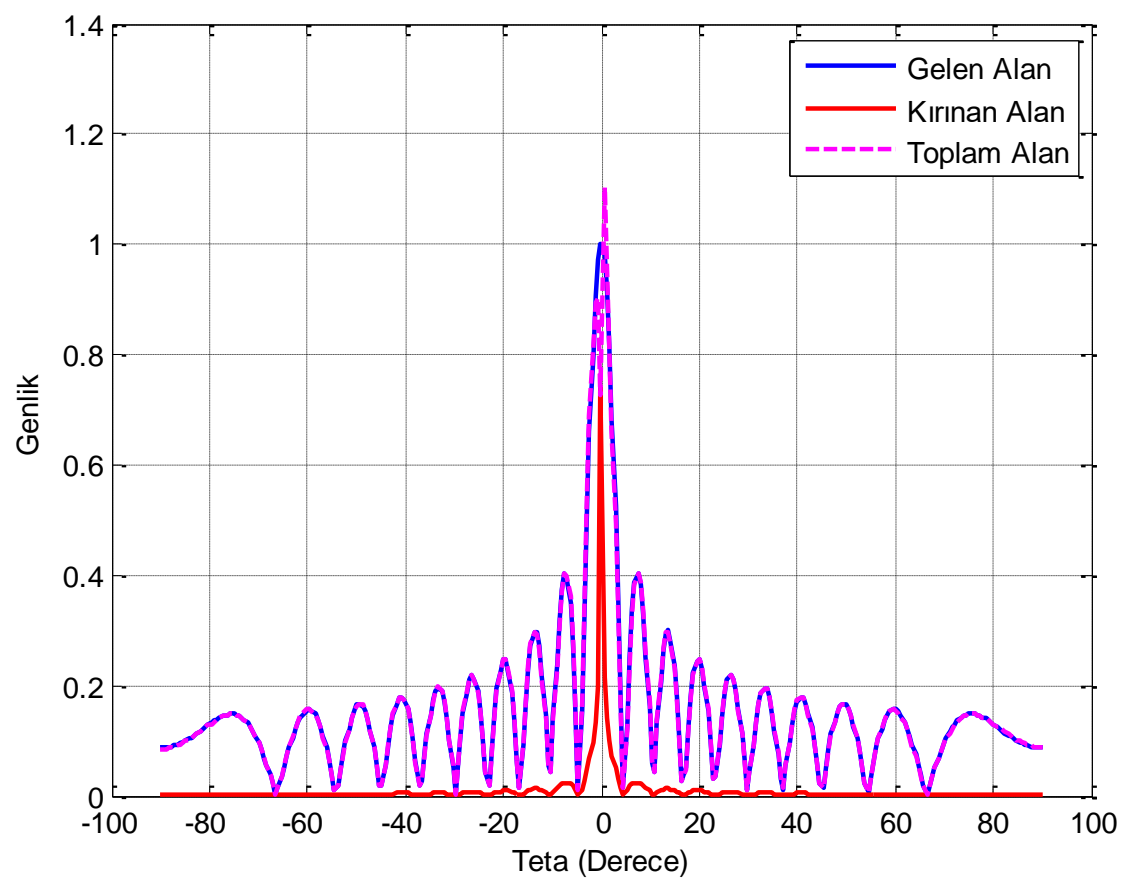

Şekil 7:

Gelen, Kırınan ve Toplam Alanlar

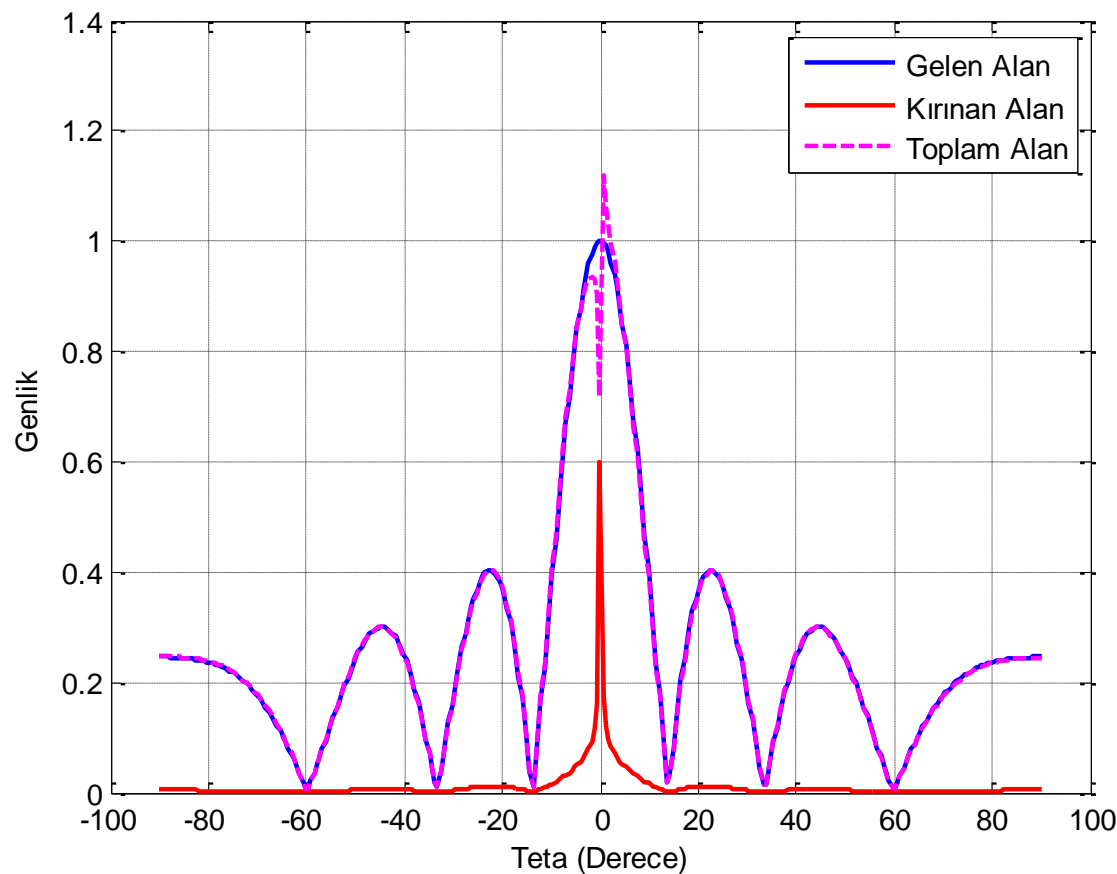

Sekil 8:

Gelen, Kirınan ve Toplam Alanları $\left(r=10 / k\right.$ ve $\left.\phi_{0}=\pi / 6\right)$ 
Yalçın U.: Sınır Kırı. Dalg. Teorisi ile Yarım Düz. Bess. Işınır. Kııın.

\section{SONUÇ}

$\mathrm{Bu}$ çalışmada ilk kez Sınır Kırınım Dalgası Teorisi ile bir yutucu yarım düzlemin kenarından kırınan Bessel ışınlarının davranışları incelenmiştir. İlk olarak yutucu yüzeye gelen Bessel ışınları tanımlanmıştır. Daha sonra bu problem için uygun olan vektör potansiyeli elde edilmiştir. Elde edilen vektör potansiyeli kullanılarak yutucu yarım düzlemden kırınan Bessel alanları hesaplanmıştır. Hesaplanan kırınan alanlar, sayısal olarak değerlendirilmek için küresel koordinatlara dönüştürülmüştür. Son olarak, küresel koordinatlara dönüştürülen kırınan Bessel 1şınlarının davranışı sayısal olarak değerlendirilmiştir. Sayısal değerlendirmelerde, elde edilen ifadelere fiziksel problemlere uygun sayısal değerler verilerek gelen, kırınan ve toplam alanlara ait grafikler elde edilmiştir. Sayısal grafikler, Bessel ışınlarının yüzeye geliş açısı ve gözlem noktasının konumu değiştirilerek çizdirilmiş ve grafiklerde görülen farklılıklar yorumlanmıştır.

\section{KAYNAKLAR}

1. Altıngöz C. ve Yalçın, U. (2013) Yutucu Kesik Silindirin Kenarından Kırınan Üniform Alanların Sınır Kırınım Dalgası Teorisi ile Hesabı, Gazi Üniversitesi MühendislikMimarlık Fakültesi Dergisi, 28(1), 85-90.

2. Durnin, J. (1987) Exact solutions for nondiffracting beams. I. The scalar theory, Journal of the Optical Society of America, 4, 651-654. https://doi.org/10.1364/JOSAA.4.000651

3. Marchand, E. W. ve Wolf, E. (1962) Boudary Diffraction Wave in the Domain of the Raygleigh-Kirchoff Diffraction Theory, Journal of the Optical Society of America, 52, 761767. https://doi.org/10.1364/JOSA.52.000761

4. McGloin, D., ve Dholakia, K. (2005) Bessel Beams: Diffraction in a New Light, Contemporary Physics, 46, 15-28. https://doi.org/10.1080/0010751042000275259

5. Miyamoto, K. ve Wolf, E. (1962a) Generalization of the Maggi-Rubinowicz theory of the Boundary Diffraction Wave-Part I, Journal of the Optical Society of America, 52, 615-625. https://doi.org/10.1364/JOSA.52.000615

6. Miyamoto, K. ve Wolf, E. (1962b) Generalization of the Maggi-Rubinowicz theory of the Boundary Diffraction Wave-Part II, Journal of the Optical Society of America, 52, 626637. https://doi.org/10.1364/JOSA.52.000626

7. Otis, G. ve Lit, J.W.Y. (1975) Edge-On Diffraction of a Gaussian Laser Beam by a SemiInfinite Plane, Applied Optics, 14, 1156-1160. https://doi.org/10.1364/AO.14.001156

8. Yalçın U. ve Altıngöz C. (2017) Uniform Scattered Fields from a Parabolic Surface with the Boundary Diffraction Wave Theory, Photonics Letters of Poland, 9(4), 125-127. doi: 10.4302/plp.v9i4.753

9. Yalçın, U. (2009) Yutucu Yarım Düzlemin Kenarından Kırınan Üniform Alanların Sınır Kırınım Dalgası Teorisi İle Hesabı, 2. Mühendislik ve Teknoloji Sempozyumu, Çankaya/Ankara, 82-88.

10. Yalçın, U. (2009a), Uniform Scattered Fields of the Extended Theory of Boundary Diffraction Wave for PEC Surfaces, Progress in Electromagnetics Research M (PIER M), 7, 29-39. doi:10.2528/PIERM09031201

11. Yalçın, U. (2009b) Scattering from Perfectly Magnetic Conducting Surfaces: The Extended Theory of Boundary Diffraction Wave Approach, Progress in Electromagnetics Research M (PIER M), 7, 123-133. doi:10.2528/PIERM09042210 
12. Yalçın, U. (2011) Analysis of Diffracted Fields with the Extended Theory of the Boundary Diffraction Wave for Impedance Surfaces, Applied Optics, 50(3), 296-301. https://doi.org/10.1364/AO.50.000296

13. Young, T. (1802) The Theory of Light and Colours, Phill. Trans. R. Soc., 20, 12-48. doi: 10.1098/rstl.1802.0004

14. Yu, Y. Z. ve Dou, W. B. (2008) Vector Analyses of Nondiffracting Bessel Beams, Progress in Electromagnetics Research Letters (PIER L), 5, 57-71. doi:10.2528/PIERL08110906 
